\title{
Possible association of a reduction in cardiovascular events with blood donation
} David G Meyers, Daniel Strickland, Pierre A Maloley, Jeanette J Seburg, Janet E Wilson,
Bruce F McManus
Departments of Internal Medicine and Preventive Medicine, Division of

Cardiovascular

Diseases, Kansas

University College of

Medicine, Kansas City,

Kansas, USA

D G Meyers

Department of

Preventive and

Societal Medicine,

Division of

Epidemiology,

University of Nebraska

College of Medicine,

Omaha, Nebraska,

USA

D Strickland

Departments of

Pharmacy Practice

and Internal Medicine,

University of Nebraska

Colleges of Pharmacy

and Medicine, Omaha,

Nebraska, USA

P A Maloley

J K Seburg

Department of

Pathology and

Laboratory Medicine,

University of British

Columbia Faculty of

Medicine, Vancouver,

British Columbia,

Canada

JE Wilson

B F McManus

Correspondence to:

Dr Meyers, Division of

Cardiovascular Diseases,

Kansas University Medical

Center, 3901 Rainbow

Boulevard, Kansas City, KS

66160-7378, USA.

email: dmeyers@kumc.edu

Accepted for publication

16 May 1997

\begin{abstract}
Background-The iron hypothesis suggests that females are protected from atherosclerosis by having lower iron stores than men, thus limiting oxidation of lipids.
\end{abstract}

Objective-To test the iron hypothesis by comparing cardiovascular event rates in whole blood donors compared with nondonors.

Design-Prospective cohort with telephone survey follow up.

Setting-The State of Nebraska, USA. Participants-A sample was selected from the Nebraska Diet Heart Survey (NDHS) restricting for age $\geqslant 40$ years and absence of clinically apparent vascular diseases at time of enrollment in to NDHS (1985-87).

Main outcome measures-The occurrence of cardiovascular events (myocardial infarction, angina, stroke), procedures (angioplasty, bypass surgery, claudication, endarterectomy), nitroglycerin use, or death (all cause mortality), and level of blood donation.

Results-Participants were 655 blood donors and 3200 non-donors who differed in education, physical activity, diabetes, and frequency of antihypertensive treatment; 889 were lost to follow up. Sixty four donors and 567 non-donors reported cardiovascular events (crude odds ratio $=0.50,95 \%$ confidence interval (CI) $0 \cdot 38-0 \cdot 66$ ). The benefit of donation was confined to non-smoking males (adjusted odds ratio $0.67, \quad 95 \%$ CI $0.45-$ 0.99). Benefit was limited to current donors (the most recent three years). No additional benefit resulted from donating more than once or twice over three years. Conclusion-In support of the iron hypothesis, blood donation in non-smoking men in this cohort was associated with reduced risk of cardiovascular events. A randomised clinical trial is warranted to confirm these findings as the observed personal health benefit of donation has public policy ramifications.

\section{(Heart 1997;78:188-193)}

Keywords: iron; atherosclerosis; ferritin; oxidation; cardiovascular events

Women experience less than half the incidence and mortality from clinical coronary heart disease (CHD) of age matched men with an approximate 10 year difference in comparable age specific rates between the sexes. ${ }^{1-2}$ The lower incidence of CHD in women has never been adequately explained. Oestrogen associated changes, perhaps through effects on lipids or vasoreactivity, may be protective. $^{3}$ Observations from the Framingham cohort have suggested that the risk of CHD in women is increased equally by natural menopause, simple hysterectomy, or bilateral oophorectomy. ${ }^{4}$ Factors other than oestrogen may be important in female resistance to atherosclerotic disease.

The "iron hypothesis" suggests that menstrual iron loss protects women against $\mathrm{CHD} .^{5}$ Oxygen free radicals promote oxidation of lipids, which has been postulated to be involved in the development of atherosclerosis. ${ }^{6}$ The iron catalysed Fenton reaction generates a range of potent oxidants that can induce oxidation of lipids. ${ }^{78}$ Thus, by providing a source of free iron, replete iron stores might increase the risk of CHD. Conversely, menstrual depletion of body iron may diminish oxidation and resultant atherosclerotic CHD.

Depletion of iron through blood donation may reduce $\mathrm{CHD}$ among donors. ${ }^{9}$ We report the results of a study to examine the effects of blood donation on vascular events.

\section{Methods}

SUBJECTS

The study subjects were a restricted sample of the Nebraska Diet Heart Study (NDHS), ${ }^{10}$ a cross sectional population sample drawn between 1985 and 1987 that involved 9689 population density based and demographically representative men, women, and children from Nebraska, USA. Ages ranged from four months to 98 years (mean $43 \cdot 1$ ). Males comprised $52.8 \%$ of the sample. During 1992-93 participants in the NDHS were recontacted for the current study if they were $\geqslant 40$ years old and denied clinically manifest cardiac, cerebral, or peripheral vascular disease in the 1985-87 NDHS survey. The restricted follow up cohort comprised 4762 healthy individuals, $52.5 \%$ male, mean age 56.8 years at time of enrollment in NDHS. Follow up was successful in 3873 people $(81 \cdot 3 \%)$. Eighteen refused to participate and 889 were lost to follow up in spite of a minimum of six attempts at telephone contact, repeat searches of telephone listings, contact with local relatives or residents with the same surname, and searches for current addresses by the United States Postal Service and Equifax Services (Atlanta, Georgia, USA). Other national databases were not used because of lack of unique subject identifiers in the NDHS database. 
DATA ACQUISITION

Between 1985 and 1987, on-site interviews, physical examinations, and blood sampling were performed under supervision of NDHS medical personnel by local professional and lay volunteers at 60 sites throughout Nebraska. A standardised health status assessment questionnaire was administered. Height, weight, and a single cuff blood pressure were measured. Fasting venous blood was drawn and shipped unfrozen in clot tubes to a Centers for Disease Control and Prevention standardised lipid laboratory where total cholesterol, high density lipoprotein (HDL) cholesterol, triglycerides, and glucose concentrations were determined after centrifugation, using a Technicon SMAC analyser (Technicon Corp, Terrytown, New York, USA). Low density lipoprotein (LDL) cholesterol concentrations were calculated using the Friedewald equation. ${ }^{11}$

\section{FOLLOW UP}

Between October 1992 and November 1993, medically trained interviewers contacted participants by telephone. In consenting participants, a computer assisted structured questionnaire, as approved by the Institutional Review Board of the University of Nebraska, was administered. This consisted of 39 items querying: demographics; occurrence of specific cardiac and vascular diseases and procedures; cardiovascular risk factors; frequency of alcohol and tobacco use; use of nitroglycerin, antihypertensives, and lipid modifying drugs; history of hysterectomy or oophorectomy and menopausal status in women; and a crude food frequency instrument (servings per week of specific food items). Participants were also asked whether they used multivitamin or iron supplements and, if so, to read the iron dose from the label or to recall the exact type and brand so that doses could be determined from a catalogue of multivitamin labels. Deaths were ascertained by telephone interview with a surviving family member or through a search of the Nebraska State Department of Health death certificate files. Surviving family members were invited to answer as many questionnaire items as possible based on their memory of the decedent's medical history.

\section{EVENTS AND PROCEDURES}

Events were defined as new onset (since 1985-87) of myocardial infarction, angina pectoris, stroke, or claudication, or treatment with percutaneous transluminal coronary angioplasty (PTCA), coronary artery bypass grafting (CABG), peripheral arterial bypass or angioplasty, carotid endarterectomy, or nitroglycerin use. Medical records were not obtained. Any death certificate listing of cardiovascular disease (ICD-9 codes 410, 411, 412, 413, 414, 429.2, $443 \cdot 9,440,443,437$, or $557 \cdot 1$ ) was considered evidence of disease.

\section{BLOOD DONATION STATUS}

During the follow up interview, participants were asked whether they had donated whole blood in the preceding 10 years. If answered affirmatively, they were then asked to read from their donor cards or to recall the number of donations in the most recent three years.

\section{STATISTICAL METHODS}

Participant characteristics were evaluated by analysis of variance, Student's $t$ test, and contingency table analysis with $\chi^{2}$ test. Crude and adjusted odds ratios were calculated using contingency table analysis and logistic regression. A logistic regression model, with presence of incident cardiac or vascular events as the outcome variable, included as independent variables:

Table 1 Subject characteristics

\begin{tabular}{|c|c|c|c|c|}
\hline & Donors & Non-donors & Total & $P$ \\
\hline Male & 435 & 1613 & $2048(53 \cdot 3 \%)$ & \\
\hline Female & 220 & 1587 & $1807(46 \cdot 7 \%)$ & $<0.001$ \\
\hline $\begin{array}{l}\text { Age (years) mean (SD) } \\
\text { (range) }\end{array}$ & $\begin{array}{l}57 \cdot 46(10 \cdot 91) \\
(40-85)\end{array}$ & $\begin{array}{l}57 \cdot 43(10 \cdot 89) \\
(40-103)\end{array}$ & $\begin{array}{l}57 \cdot 43(10 \cdot 89) \\
(40-103)\end{array}$ & 0.978 \\
\hline Body mass index $\left(\mathrm{kg} / \mathrm{m}^{2}\right)$ mean $(\mathrm{SD})$ & $26 \cdot 37(4 \cdot 05)$ & $26 \cdot 14(4 \cdot 31)$ & $26 \cdot 18(4 \cdot 26)^{\star}$ & $0 \cdot 204$ \\
\hline (range) & $(16 \cdot 81-47 \cdot 51)$ & $(14 \cdot 11-54 \cdot 20)$ & $(14 \cdot 10-54 \cdot 20)$ & \\
\hline $\begin{array}{l}\text { Education (years) mean (SD) } \\
\text { (range) }\end{array}$ & $\begin{array}{l}13.04(3 \cdot 33) \\
(4-20)\end{array}$ & $12.57(3 \cdot 21)$ & $12 \cdot 65(3 \cdot 24)$ & $<0.001$ \\
\hline Exercise (\%) & $479(73 \cdot 13)$ & $1881(58 \cdot 78)$ & $2357(61 \cdot 14)$ & $<0.001$ \\
\hline $\begin{array}{l}\text { Alcohol (drinks/weeks) mean (SD) } \\
\text { (range) }\end{array}$ & $2 \cdot 42(1 \cdot 75)$ & $2 \cdot 32(1 \cdot 80)$ & $2.34(1.79)$ & $0 \cdot 234$ \\
\hline \multicolumn{5}{|l|}{ Cigarette use (\%) } \\
\hline Current & $57(8 \cdot 70)$ & $290(9 \cdot 06)$ & $347(9 \cdot 00)$ & \\
\hline $\begin{array}{l}\text { Past } \\
\text { Never }\end{array}$ & $\begin{array}{l}249(38 \cdot 01) \\
349(53 \cdot 28)\end{array}$ & $\begin{array}{l}1139(35 \cdot 50) \\
1771(53 \cdot 34)\end{array}$ & $\begin{array}{l}1388(36 \cdot 00) \\
2120(54 \cdot 99)\end{array}$ & 0.519 \\
\hline $\begin{array}{l}\text { Systolic blood pressure (mm Hg) mean (SD) } \\
\text { (range) }\end{array}$ & $\begin{array}{l}133 \cdot 63(18 \cdot 21) \\
(86-206)\end{array}$ & $\begin{array}{l}134 \cdot 22(18 \cdot 29) \\
(86-222)\end{array}$ & $\begin{array}{l}134 \cdot 12(18 \cdot 28) \\
(86-222)\end{array}$ & 0.430 \\
\hline $\begin{array}{l}\text { Diastolic blood pressure (mm Hg) mean (SD) } \\
\text { (range) }\end{array}$ & $\begin{array}{l}81 \cdot 94(10 \cdot 52) \\
(50-112)\end{array}$ & $\begin{array}{l}82 \cdot 61(10 \cdot 25) \\
(50-106)\end{array}$ & $\begin{array}{l}82 \cdot 49(10 \cdot 30) \\
(50-112)\end{array}$ & $0 \cdot 168$ \\
\hline Hypertension treatment (\%) & $120(18 \cdot 32)$ & $864(27 \cdot 00)$ & $984(25 \cdot 52)$ & $<0.001$ \\
\hline $\begin{array}{l}\mathrm{LDL} \text { cholesterol }(\mathrm{mg} / \mathrm{dl}) \text { mean }(\mathrm{SD}) \\
\text { (range) }\end{array}$ & $\begin{array}{l}150 \cdot 59(42 \cdot 55) \\
(28-399)\end{array}$ & $\begin{array}{l}150 \cdot 35(38 \cdot 79) \\
(37-379)\end{array}$ & $\begin{array}{l}150 \cdot 39(39 \cdot 48) \\
(28-399)\end{array}$ & 0.967 \\
\hline $\begin{array}{l}\text { HDL cholesterol (mg/dl) mean (SD) } \\
\text { (range) }\end{array}$ & $55 \cdot 15(15 \cdot 05)$ & $53.97(14 \cdot 48)$ & $54 \cdot 18(14 \cdot 59)$ & 0.070 \\
\hline Triglycerides (mg/dl) mean (SD) & $141 \cdot 12(89 \cdot 05)$ & $\begin{array}{l}(21-115) \\
133 \cdot 04(84 \cdot 84)\end{array}$ & $\begin{array}{l}(20-116) \\
138 \cdot 58(85 \cdot 59)\end{array}$ & $0 \cdot 418$ \\
\hline Lipid treatment (\%) & $41(6 \cdot 26)$ & $263(8 \cdot 22)$ & $\begin{array}{l}(27-756) \\
304(7 \cdot 88)\end{array}$ & 0.90 \\
\hline $\begin{array}{l}\text { Glucose }(\mathrm{mg} / \mathrm{dl}) \text { mean }(\mathrm{SD}) \\
\text { (range) }\end{array}$ & $\begin{array}{l}95 \cdot 44(19 \cdot 43) \\
(64-3001)\end{array}$ & $\begin{array}{l}96 \cdot 16(23 \cdot 54) \\
(46-355)\end{array}$ & $\begin{array}{l}96 \cdot 03(22 \cdot 86) \\
(46-355)\end{array}$ & 0.438 \\
\hline Diabetes (\%) & $6(0.92)$ & $175(5 \cdot 47)$ & $181(4 \cdot 69)$ & $<0.001$ \\
\hline Relatives with CHD (\%) & $\begin{array}{l}9 \cdot 75(14 \cdot 30) \\
(0-100)\end{array}$ & $\begin{array}{l}9 \cdot 90(14 \cdot 13) \\
(0-100)\end{array}$ & $\begin{array}{l}9 \cdot 88(14 \cdot 16) \\
(0-100)\end{array}$ & 0.814 \\
\hline Vitamin use (\%) & $220(33.59)$ & $1155(36.09)$ & $1375(35 \cdot 67)$ & $0 \cdot 223$ \\
\hline
\end{tabular}

CHD, coronary heart disease; HDL, high density lipoprotein; LDL, low density lipoprotein. 
Table 2 Cardiovascular events and procedures

\begin{tabular}{lccr}
\hline Event & Donors $(n=655)$ & Non-donors $(n=3200)$ & P value \\
\hline Angina & $24(8 \cdot 66 \%)$ & $253(17.64 \%)$ & $<0.001$ \\
Myocardial infarction & $12(9 \cdot 45 \%)$ & $115(17.25 \%)$ & 0.022 \\
PTCA & $5(5.68 \%)$ & $83(17.26 \%)$ & 0.002 \\
CABG & $6(8 \cdot 11 \%)$ & $68(17.16 \%)$ & 0.022 \\
Claudication/bypass/ & & & \\
angioplasty/endarterectomy & $29(11.24 \%)$ & $229(17.40 \%)$ & 0.010 \\
Stroke & $5(5.56 \%)$ & $85(17.26 \%)$ & 0.001 \\
Nitroglycerin use & $7(5.79 \%)$ & $114(17.35 \%)$ & $<0.001$
\end{tabular}

Subjects are classified by their single most profound vascular event: myocardial infarction $>$ stroke > CABG > PTCA > angina > claudication > nitroglycerin.

CABG, coronary artery bypass graft; PTCA, percutaneous transluminal coronary angioplasty.

blood donation status plus five cardiovascular risk factors (education level, physical activity, lipid disorders, hypertension, and diabetes mellitus). Alpha significance was $\mathrm{P}<0.05$, twotailed.

\section{Results}

\section{SUBJECT CHARACTERISTICS}

Follow up over the five to eight year interval was completed in 3855 individuals (2048 males $(53.3 \%)$ and 1807 females $(46.7 \%)$ ) aged (SD) $63.95 \quad(10.89)$ years (range, 45-103) at time of follow up (table 1). Over $94 \%$ were of European origin, 3\% Asian, $1.4 \%$ Native American, and 1\% African. Donors were more likely to be male, consume more alcohol, have slightly higher HDL cholesterol concentrations, exercise at least once a week, and use vitamins (all $P<0.01$ ). The 889 non-responders exercised least and had the lowest prevalence of alcohol use, the highest systolic blood pressure, the lowest HDL cholesterol, the highest prevalence of diabetes mellitus, and used vitamins least (all $P$ $<0.01)$. Surveyed dietary intake (1992-93) was similar between donors and non-donors except that donors consumed meat more frequently (consumed daily by $27.57 \%$ of donors $v 22.42 \%$ of non-donors, $\mathrm{P}=0.033$ ).

\section{BLOOD DONOR STATUS}

Six hundred and fifty five participants $(17 \cdot 0 \%)$ reported donating at least one unit of whole blood in the previous 10 years. Among currently active donors, 145 donated one or two units, 131 donated three to five units, and 122

Table 3 Odds ratios for cardiovascular events and procedures in whole blood donors

\begin{tabular}{|c|c|c|}
\hline & Number & Odds ratio $(95 \%$ CI) \\
\hline Men & 2048 & $0.70(0.48,0.99)^{\star}$ \\
\hline Current smokers & 186 & $1.01(0.34,3.04)^{\star}$ \\
\hline Past smokers & 828 & $0.68(0.40,1.39)^{\star}$ \\
\hline Never smokers & 1034 & $0.67(0.45,0.99)^{\star}$ \\
\hline $\begin{array}{l}\text { Non-smoking with } \mathrm{LDL} \\
\text { cholesterol } \leqslant 130 \mathrm{mg} / \mathrm{dl}\end{array}$ & 429 & $0.95(0.49,1.84)^{\star}$ \\
\hline $\begin{array}{l}\text { Non-smoking with LDL } \\
\text { cholesterol > } 160 \mathrm{mg} / \mathrm{dl}\end{array}$ & 468 & $0.62(0.33,1.17)^{\star}$ \\
\hline Women & 1807 & $0.84(0.51,1.38)^{\star}$ \\
\hline Current smokers & 161 & $0.66(0.08,5.05)^{\star}$ \\
\hline $\begin{array}{l}\text { Past smokers } \\
\text { Never smokers }\end{array}$ & $\begin{array}{r}560 \\
1086\end{array}$ & $\begin{array}{l}0.83(0.33,2.08)^{\star} \\
0.85(0.51,1.42)^{\star}\end{array}$ \\
\hline $\begin{array}{l}\text { Non-smoking with } \mathrm{LDL} \\
\text { cholesterol } \leqslant 130 \mathrm{mg} / \mathrm{dl}\end{array}$ & 366 & $0.64(0.24,1.71)^{\star}$ \\
\hline $\begin{array}{l}\text { Non-smoking with LDL } \\
\text { cholesterol }>160 \mathrm{mg} / \mathrm{dl} \\
\text { Overall }\end{array}$ & 424 & $0.96(0.46,2.04)^{\star}$ \\
\hline $\begin{array}{l}\text { Crude } P<0.01 \\
\text { Adjusted }^{\star} P=0.087\end{array}$ & 3855 & $\begin{array}{l}0.50(0.38,0.66) \\
0.77(0.57,10.03)^{\star}\end{array}$ \\
\hline
\end{tabular}

${ }^{\star}$ Logistic model $-\log$ vascular events $=$ donor status, education level, physical activity, presence of lipid disorder, hypertension, diabetes mellitus. donated more than five units over the most recent three years.

\section{CARDIOVASCULAR EVENTS/DEATHS}

Cardiovascular events or procedures, or use of nitroglycerin were reported by 64 donors $(9.77 \%)$ and 567 non-donors $(17.72 \%)(\mathrm{P}<$ 0.001 ) (table 2). While most reported a single event $(n=394), 125$ noted two events, 64 three events, 33 four events, 12 five events, one noted six events, and two reported seven events over the follow up period. Specific events were from 1.6 to 3.3 times more frequent in non-donors than donors (all $\mathrm{P}<$ 0.022 ). The mortality rate for the whole cohort was $9 \cdot 3 / 1000$ (approximately $1 \cdot 4 / 1000$ / year), including 13 deceased individuals with known vascular diseases; 16 others died of cancer and seven died of other causes but without concurrent vascular disease.

\section{ASSOCIATION OF BLOOD DONATION WITH}

\section{VASCULAR EVENTS}

The crude odds ratio for events in whole blood donors compared with non-donors in the past 10 years was 0.50 (95\% confidence interval (CI) $0.38-0.66 ; \mathrm{P}<0.001$ ) (table 3). After adjustment for the five covariates (education level, physical activity, lipid disorders, hypertension, diabetes mellitus) the adjusted odds ratio was $0.77(95 \%$ CI $0.57-1.03)$. The beneficial effect of donation was confined to men (odds ratio $=0.70 ; 95 \%$ CI $0.48-0.99 v$ odds ratio $=0.84 ; 95 \% \mathrm{CI} 0.51-1.38$ for women). Among men, current cigarette smoking negated any benefit of donation (odds ratio = 1.01 ) while past smokers (odds ratio $=0.68$ ) had a similar event experience as those who had never smoked (odds ratio $=0.67$ ) (table 3 ). The benefit of donation was greater in men with serum LDL cholesterol concentrations $>160 \mathrm{mg} / \mathrm{dl}$ than in those with values $\leqslant 130$ $\mathrm{mg} / \mathrm{dl}$, although all confidence intervals were wide.

Compared with non-donors, there was no decrease in events in male donors who had not donated in the most recent three years (odds ratio $=1 \cdot 14,95 \%$ CI 0.68-1.92). Among current donors, the dose response relation was flat. At three levels of donation over three years $(1-2,3-5$, and $>5$ times) the odds ratios did not differ significantly (odds ratios $=0.21$ (95\% CI $0.10-0.76), 0.79$ (95\% CI $0.42-$ 1.51 ), 0.50 (95\% CI 0.23-1.09), respectively). No significant effect on events by blood donation was observed in women (table 3). No interactions of donation with either smoking or lipid status were observed in women; no difference was observed between non-donors and any level of donation. Among women, $29.9 \%(n=540)$ were $\leqslant 53$ years old. The odds ratio for events in female blood donors versus similar aged non-donors $\leqslant 53$ years old was $0.56(95 \% \mathrm{CI} 0.21-1.52)$ compared with $0.97(95 \%$ CI $0.50-1.88)$ for donors versus non-donors $>53$ years old.

Iron supplementation did not confound the blood donation effect. The overall crude odds ratio $=0.60(95 \%$ CI $0.46-0.78)$ in nonsupplementers compared with 0.36 (95\% CI 
$0 \cdot 18-0.73)$ in iron supplemented people (Mantel-Haenszel $\chi^{2} \mathrm{P}=0 \cdot 18$ ). Nor was there a consistent effect from red meat consumption (haem iron). The odds ratio for donation was 0.94 for people with daily meat consumption, compared with 0.52 for at least weekly consumption and 0.99 for less than weekly consumption (Mantel-Haenszel test for trend $P=0.78$ ).

\section{Discussion}

Atherosclerotic lesions are rich in iron and the gruel from these lesions induces lipid peroxidation. ${ }^{12}$ In cultured macrophages there is a dose-dependent two- to fourfold increase in lipid peroxidation with iron exposure. ${ }^{13}$ In animals, iron increases the suspectibility to oxygen reperfusion damage. ${ }^{14}$ Desferrioxamine, a chelator of iron, protects tissue from oxidation damage. ${ }^{15} 16$ Iron depletion is associated with strong antioxidant effects. ${ }^{17}$

The serum of iron deficient nomads inhibits lipid oxidation, ${ }^{18}$ an effect lost with iron repletion. ${ }^{19}$ Across European populations there is a high degree of correlation between CHD mortality and hepatic iron stores $(r=0 \cdot 72) .{ }^{20}$ The Nutrition Canada Survey demonstrated a significant association between CHD mortality and serum iron concentrations. ${ }^{21}$

Ferritin, a hollow spheroidal protein, is the major storage site for iron..$^{22}$ It is found in all tissues but especially the liver, spleen, and bone marrow. Because serum ferritin concentrations are directly proportional to intracellular ferritin concentrations, it is currently the best clinical measure of body iron stores. ${ }^{22}$ Serum ferritin concentrations in normal healthy menstruating women are approximately half those of men (34-50 $v 54-128 \mu \mathrm{g} / \mathrm{l})$ and rise substantially, nearly doubling, after menopause. ${ }^{23}{ }^{24}$ With blood donation, ferritin concentrations of men approach those of premenopausal women.

In the Kuopio Ischemic Heart Disease Risk Factor Study, Salonen and coworkers ${ }^{25}$ followed for three years 1931 randomly selected men with no symptomatic CHD at entry. The risk of acute myocardial infarction in men with serum ferritin $>200 \mu \mathrm{g} / 1$ was $2 \cdot 2$-fold higher than those with lower serum ferritin $(P<$ 0.01 ). Using carotid duplex ultrasound, Kiechl and coworkers ${ }^{26}$ found a strong association between atherosclerosis and serum ferritin $(P<0.001)$ in a cross sectional study of 847 Austrians.

Most pertinent to blood donation, Salonen and associates ${ }^{27}$ studied the effect of phlebotomy on the oxidation resistance of serum lipoprotein in 14 Finnish men with raised serum ferritin concentrations. After phlebotomy of $450 \mathrm{mg}(500 \mathrm{ml})$ of blood three times in 14 weeks, serum ferritin concentration was reduced from 209 to $74 \mu \mathrm{g} / 1$ with no change in serum iron. Maximal oxidation velocity was decreased by $20 \%(P=0.032)$ and the lag time to start of oxidation was lengthened by $30 \%(P=0.032)$, demonstrating increased oxidation resistance with phlebotomy reduced ferritin concentrations.
Recently, Salonen and coworkers reported that blood donation reduced the risk of myocardial infarction by $86 \%$ among a prospective cohort of 2682 Finnish males followed for a mean of 5.5 years. $^{28}$ Infarctions occurred in one $(0.7 \%)$ of 153 donors compared with $22(9.8 \%)$ of the non-donors $(P<$ 0.001).

Results of several studies have not supported the iron hypothesis. The Johns Hopkins Hospital autopsy registry found less coronary artery disease in those with haemochromatosis or haemosiderosis compared with age and sex matched controls. ${ }^{29}$ Case-control studies have found no significant association between $\mathrm{CHD}$ and serum ferritin. ${ }^{30-32}$

The iron hypothesis suggests that the antiatherosclerotic effects of blood donation should be more evident in men because of their larger iron stores. ${ }^{9}$ Our results conform to that prediction. Donation of one unit of whole blood reduces body iron by about 250 mg. ${ }^{33}$ In males, donation of one or two units of blood profoundly lowers serum ferritin concentrations to slightly greater than those of premenopausal women. ${ }^{23} 2433$ Donation produces a much smaller decrease in serum ferritin concentrations in women. ${ }^{33}$

The lack of effect of donation in smokers, as observed in the current study, has been reported by other investigators of antioxidants. ${ }^{3435}$ Interestingly, Salonen and associates $^{27}$ demonstrated beneficial effects of blood letting on serum oxidation in smokers. It is possible that while smoking does not directly effect oxidation processes, it blocks the expression of clinical benefits derived from lessened oxidation though other mechanisms such as increased platelet aggregation or endothelial dysfunction. ${ }^{36}$

We observed synergy between blood donation and raised concentrations of LDL cholesterol with the greatest benefit from donation occurring in non-smoking men with raised LDL cholesterol. This has been noted in other studies. ${ }^{192526}$ Atherogenesis would be accelerated by the combination of high LDL cholesterol and high iron concentrations if oxidation of LDL cholesterol is truly a critical step in atherogenesis. ${ }^{1415}$

In the current study, donating more than one or two times over three years resulted in no further reduction in events. Studies of ferritin concentrations after multiple whole blood donations reveal a similar effect-that is, ferritin concentrations may not show a dose dependent reduction associated with the number of donations by people who give blood regularly. ${ }^{33}$ Thus, in male occasional donors, ferritin concentrations (and total body iron) remain at concentrations slightly above those of premenopausal women. Body iron is tightly controlled by gastrointestinal absorption of iron. ${ }^{37}$ It appears that while absorption increases at very low ferritin concentrations, it does not increase in men with concentrations of $70-80 \mu \mathrm{g} / 1 .{ }^{38}$ Thus, mild to moderate iron depletion in men, as in women, does not stimulate iron repletion. 
Control of gastrointestinal iron absorption may explain why neither supplementation of elemental iron nor consumption of haem iron (red meat) had significant effects. In iron replete individuals, gastrointestinal iron absorption is virtually nil. ${ }^{37-39}$ The observational studies that failed to detect an association between iron intake (either dietary or supplemental) and cardiovascular events undoubtedly studied iron replete subjects. ${ }^{4041}$

We observed no significant donation effect in postmenopausal women. As a donation effect would be expected, it is likely that the number of women observed in our study was insufficient to show any effect. A sample of more than 100000 women would be necessary to detect a $50 \%$ donation benefit with $95 \%$ confidence, given the observed event prevalence of 160 per 1000 .

Studies using haemoglobin, haematocrit, serum iron, transferrin concentrations, or transferrin saturation have given conflicting results. ${ }^{39-43}$ This is not unexpected as none of these parameters accurately reflect body iron. ${ }^{22}$ Donation of increasing amounts of whole blood has no effect on these parameters. ${ }^{2324} 27$

Ferritin is an acute phase reactant-concentrations increase with inflammation. Several studies have used a case-control design with myocardial infarction as the disease indicator. ${ }^{25} 30$ It is possible that these results were confounded by the inflammation associated with infarction or other processes. However, using other disease indicators, three case-control studies also found a lack of association. ${ }^{31} 32$ A single prospective cohort study with myocardial infarct as the indicator examined ferritin concentrations in 2036 participants and found no association. ${ }^{34}$ Studies might fail to reveal an association if there exists a threshold ferritin concentration for cardiovascular effects.

Our results may be limited by the lack of confirmation of vascular events and the timing of donation relative to the vascular event. We are confident that coronary bypass surgery, angioplasty, and endarterectomy were accurately recalled by the participants. Studies of self reported myocardial infarction compared with medical records report validation rates of $56-84 \%$, with few false negative reports. ${ }^{44}$ False positive reports of myocardial infarction resulted from erroneous reporting of unstable angina and coronary insufficiency. As these entities were included in our overall event rate, any participant misclassification from erroneous recall would have no effect on the association of donation with events. Recall bias from false negative participant responses would only bias the association towards the null. That the event preceded blood donation is unlikely as donation over a 10 year period was sought and participants were without events at onset of follow up (five to eight years). Additionally, participants suffering events would probably have been prohibited from donation. The importance of dietary data is minimal as dietary iron has no major relevance in iron replete persons. ${ }^{37} 38$
The low mortality rate observed in the cohort results from the study being restricted to persons without clinically apparent disease at entry. Selection of a healthy cohort would minimise the apparent effect of blood donation. It is possible that the low event rate observed also resulted from the loss to follow up of 889 individuals who, because of retirement or infirmity, may have moved out of Nebraska. Many of the characteristics differing among the donors, non-donors, and nonrespondents (sex, exercise, alcohol, systolic blood pressure, and vitamin supplementation) did not differ to an important extent. Thus, it is unlikely that those lost to follow up differed in their frequency of blood donation or vascular event rate. Larger differences such as frequency of exercise and prevalence of both hypertension and diabetes mellitus may influence the results, although these potential confounders were adjusted for in the logistic model. A more difficult problem is the likely self selection of healthier persons as donors who thus have a survival advantage over nondonors. ${ }^{45}$ This in part stems from both a probable increased health consciousness among donors and the institutional prohibition of unhealthy donors. Our donors consumed more alcohol, had higher HLD cholesterol, and lower systolic blood pressure than nondonors. It is unlikely that the donors were truly healthier or more health conscious than non-donors as no important differences were observed in body mass index, education, cigarette use, concentrations of LDL cholesterol or triglycerides, use of iron supplements, or diet. Indeed, donors ate red meat more frequently than non-donors. Nonetheless, we cannot completely exclude the possibility that the donor advantage was due in part to selection of healthier individuals.

We used a prospective approach to study iron depletion in a large representative sample of healthy middle-aged and elderly people. The important covariates such as known cardiovascular risk factors and dietary intake were assessed. The results corroborate and extend observations on the iron hypothesis. The current study identified a lack of effect in women and a flat dose-response relation in men, as predicted by known effects of blood donation on stored iron concentrations. The observed reduction in incident vascular events might be explained in two ways. Either iron depletion through blood donation truly effects atherosclerosis or blood donation selects healthy individuals inherently at very low risk for events. Definitive conclusions require a randomised clinical trial.

\section{CONCLUSION}

The impact of this study is potentially threefold. First, we have furnished evidence in support of the iron hypothesis. It follows that the results may help to explain the lower CHD rate in women. Finally, we have identified a reason, beyond altruism, for blood donationespecially among men. This last point has significant public policy ramifications. 
We thank sincerely the volunteer interviewers: Tim Augustine, Cornell Bonde, Gina Borgelt, Kevin Dicks, Rachael Fantz, Laura Gless, Roxanne Holdren, Pam Howard, Dana Hult, NHI Ho, Barb Keuter, Amy Kight, Julie Koca, Kim Kraenow, Jason Mazour, Rayma Meyers, Suzanne Munson, Shelley Patterson, Kari Pecka, Valerie Scharff, Susanne Sornson, Tammy VonKampen, and Beth Wilson. Expert manuscript preparation was done by Alfreda Taylor. We also gratefully acknowledge the biostatistical advice of Kashinath Patil, the survey technical guidance of Robert Apel, and the insightful manuscript review of James Cook.

1 Wingard DL, Suarez L, Barrett-Conner E. The sex differential in mortality from all causes and ischemic heart disential in mortality from all causes and is

2 Lerner DJ, Kannel WB. Patterns of coronary heart disease morbidity and mortality in the sexes: a 26-year follow-up of the Framingham population. Am Heart $f$ 1986;11 383-90.

3 Shewman DA. Lipids, atherosclerosis, and the postmenopausal woman. A clinical perspective. Obstet Gynecol Clin North Am 1994;21:337-55.

4 Kannel WB, Hjortland MC, McNamara PM, Gordon T. Menopause and the risk of cardiovascular disease. The Framingham Study. Ann Intern Med 1976;85:447-52.

5 Sullivan JL. Iron and the sex difference in heart disease risk. Lancet 1981;i:1293-4.

6 Steinberg D, Parathasarathy S, Casew TE, Khoo JC, Witztum JL. Beyond cholesterol: modifications of lowdensity lipoprotein that increase its atherogenicity. $N$ density lipoprotein that increas
Engl $\mathcal{Y}$ Med 1989;320:915-24.

7 Frie B. Reactive oxygen species and antioxidant vitamins: mechanism of action. Am $\mathcal{f}$ Med 1994;97(Suppl 3A): 55-135.

$8 \mathrm{McCord}$ JM. Is iron sufficiency a risk factor in ischemic heart disease? Circulation 1991;83:1112-13.

9 Sullivan JL. Blood donation may be good for the donor. Vox Sang 1991;61:161-4.

10 Holt K, Bay A, Kims C, Wilson JE, McManus BF. Dietary intake of saturated fat and cholesterol in early childhood implications for prevention of atherosclerosis [abstract]. $\mathcal{F}$ Am Coll Cardiol 1989;13(Suppl A):12A.

11 Friedewald WT, Levy RI, Fredrickson DS. Estimation of the concentration of low-density lipoprotein cholesterol in plasma without use of the preparative ultracentrifuge. Clin Chem 1972;18:449-53.

12 Smith C, Mitchinson MJ, Aruoma OI, Halliwell B. Stimulation of lipid peroxidation and hydroxyl-radical generation by the contents of human atherosclerotic generation by the contents of h
lesions. Biochem $\mathcal{F} 1992 ; 286: 901-5$.

13 Fuhrman B, Oiknine J, Aviram M. Iron induces lipid peroxidation in cultured macrophages, increases their ability to oxidative modify $\mathrm{LDL}$, and affects their secretory properties. Atherosclerosis 1994;111:65-78.

14 Van der Kraaij AMM, Mostert LJ, Van Eijk HG, Koster $\mathrm{JF}$. Iron-load increases the susceptibility of rat hearts to oxygen reperfusion damage. Circulation 1988;78:442-9.

15 Reddy BR, Kloner RA, Przyklenk K. Early treatment with deferoxamine limits myocardial ischemic/reperfusion injury. Free Radic Biol Med 1989;7:45-52.

16 William RE, Zweier JL, Flaherty JT. Treatment with deferoxamine during ischemia improves functional and metabolic recovery and reduces reperfusion-induced oxygen radical generation in rabbit hearts. Circulation 1991;8: radical gener.

17 Sullivan JL, Till GO, Ward PA. Iron depletion decreases lung injury after systemic compliment activation. Fed lung injury after

18 Murray MJ, Murray AB, Murray NJ. Do iron and copper supplementation of the diet impair antioxidant activity and speed atherogenesis? [abstract] Arterioscler Thromb 1991;11:1479.

19 Murray MJ, Murray AB, Murray NJ. Nutritional iron and copper deficiency may protect against the atherosclerosis of high-fat diets [abstract]. Arterioscler Thromb 1991;11: 1470 .

20 Lauffer RB. Iron stores and the international variation in mortality from coronary artery disease. Med Hypothesis 1991;35:96-102.

21 Morrison HI, Semenciw RM, Mao Y, Wigle DT. Serum iron and risk of fatal acute myocardial infarction. Epidemiology 1994;5:243-6.
22 Cook JD, Lipschitz DA, Miles LEM, Finch CA. Serum ferritin as a measure of iron stores in normal subjects. $A m \mathcal{F}$ Clin Nutr 1974;27:681-7.

23 Pederson NS, Morling N. Iron stores in blood donors evaluated by serum ferritin. Scand $\mathcal{H}$ Haematol 1978;20:70-6.

24 Finch CA, Cook JD, Labbe RF, Culala M. Effect of blood donation on iron stores as evaluated by serum ferritin. Blood 1977;50:441-7.

25 Salonen JT, Nyyssonen K, Korpela H, Tuomilehto J, Seppanen R, Salonen R. High stored iron levels are associated with excessive risk of myocardial infarction in eastern Finnish men. Circulation 1992;86:803-11.

26 Kiechl S, Aichner F, Gerstenbrand F, Egger G, Mair A Rungger G, et al. Body iron stores and presence of Rungger G, et al. Body iron stores and presence of
carotid atherosclerosis. Arterioscler Thromb 1994;14: carotid a.

27 Salonen JT, Korpela H, Hyyssonen K, Porkkala E, Tuomainen TP, Belcher JD, et al. Lowering of body iron stores by blood letting and oxidation resistance of serum lipoproteins: a randomized cross-over trial in male smokers. F Intern Med 1995;237:161-8.

28 Tuomainen TP, Salonen R, Nyyssonen K, Salonen JT Cohort study of relation between donating blood and risk of myocardial infarction in 2,682 men in eastern Finland. BMF 1997;314:793-4.

29 Miller M, Hutchins, GM. Hemochromatosis, multiorgan hemosiderosis, and coronary artery disease. $\mathscr{f} A M A 1994$; 272:231-3.

30 Regnstrom J, Tornvall P, Kallner A, Nilsson J, Hamsten A. Stored iron levels and myocardial infarction at young age. Atherosclerosis 1994;106:123-5.

Atherosclerosis 1994;106:123-5. AM, Campeau L. The place of ferritin among risk factors AM, Campeau L. The place of ferritin among risk factors associated with

32 Moore M, Folsom AR, Barnes RW, Eckfeldt JH. No association between serum ferritin and asymptomatic carotid atherosclerosis. Am $\mathcal{F}$ Epidemiol 1995;141:719-23.

33 Ledue TB, Craig WY, Ritchie RF, Haddon JE. Influence of blood donation and iron supplementation on indicators of iron status. Clin Chem 1994;40:1345-6.

34 Rimm EB, Stampfer MJ, Ascherio A, Giovannucci E Golditz GA, Willett WC. Vitamin E consumption and the risk of coronary heart disease in men. $N$ Engl f $\mathrm{Med}$ 1993;328:1450-6.

35 The Alpha-Tocopherol, Beta Carotene Cancer Prevention Study Group. The effect of vitamin $\mathrm{E}$ and beta carotene on the incidence of lung cancer and other cancers in male smokers. N Engl f Med 1994;330:1029-35.

36 Davis J, Shelton, Eigenber D, Hignite CE, Watanabe IS. Effects of tobacco and non-tobacco cigarette smoking IS. Effects of tobacco and non-tobacco cigarette smoking on endothelium

37 Cook JD, Skikne BS. Intestinal regulation of body iron. Blood Reviews 1987;1:267-72.

38 Gary PJ., Koehler KM, Simon TL. Iron stores and iron absorption: effects of repeated blood donations. $A m \mathcal{F}$ Clin Nutr 1995;62:611-20.

39 Koster JF, Sluiter W. Is increased tissue ferritin a risk factor for atherosclerosis and ischemic heart disease? Br Heart 1995;73:208.

40 Liao Y, Cooper RS, McGee DL. Iron status and coronary heart disease: negative findings from the NHANES I Epidemiologic follow-up study. Am $f$ Epidemiol 1994; 139:704-12.

41 Reunanen A, Takkunen H, Knekt P, Seppanen $R$ Aroumaa A. Body iron stores dietary iron intake and Aroumaa A. Body iron stores dietary iron intake and 223-30.

42 Wannamethee G, Shaper AG, Whincup PH. Ischemic heart disease: association with hematocrit in the British Regional Heart Study. F Epidemiol Comm Health 1994;48 112-18.

43 Wannamethee G, Perry IJ, Shaper AG. Haematocrit, hypertension and risk of stroke. $\mathcal{F}$ Intern Med 1994;235 163-8.

44 Rosamand WB, Sprafka M, McGovern PG, Nelson M Leupker RV. Validation of self-reported history of acute myocardial infarction: experience of the Minnesota heart survey registry. Epidemiology 1995;6:67-9.

45 Casale G, Bignamini, deNicola $P$. Does blood donation prolong life expectancy. Vox Sang 1983;45:398-9. 